\title{
infertil erkek populasyonda cinsel disfonksiyonun psikosomatik yansımaları
}

\section{Psychosomatic reflections of sexual dysfunction in the infertile male population}

\author{
Ünal Öztekin®, Fatih Fırat²®
}

\section{öz}

AMAÇ: Bu çalışmada, primer erkek infertilitesi araştırılmak üzere başvuran hastalarda erektil fonksiyon skoru ile depresyon ve bedensel duyumları abartma arasındaki ilişkinin değerlendirilmesi amaçlanmıştır.

GEREÇ ve YÖNTEM: Çalışmaya, Şubat 2019-Mayıs 2019 tarihleri arasında üroloji polikliniğine infertilite araştırılması nedeniyle başvuran 200 primer infertil hasta dahil edildi. IIEF <26 $(n=61)$ ve IIEF $\geq 26$ ( $n=139)$ olmak üzere hastalar iki gruba ayrılarak değerlendirildi. Gruplar arasında sosyodemografik veriler ve psikiyatrik ölçek skorları (Beck Depresyon Inventory, Somatosensory Amplification Scale) karşılatırılarak, korelasyon analizleri yapıldı.

BULGULAR: Hastaların yaş aralığı 18-45 (mean: 30,1) idi. IIEF $\geq 26$ olan grupta ortalama infertilite süresi 21.6 ay idi ve istatistiksel olarak anlamlı fark mevcuttu $(\mathrm{p}<0,001)$. İki grup arasında SSAS ve BDI skorları karşılaştıııldığında, her iki skor IIEF < 26 olan grupta anlamlı derecede yüksek olarak tespit edildi ve sırası ile $25,93 \pm 6,91,14,77 \pm 7,87$ idi $(\mathrm{p}=0,024, \mathrm{p}<0,001)$. IIEF skoru, SSAS ve BDI skorları ile anlamlı negatif korele idi. İnfertilite süresi, SSAS ve BDI ile pozitif, IIEF ile negatif korele bulundu.

SONUÇ: Erkek faktörlü infertilitede, cinsel işlev bozukları görülebilir. Bu bozukluklar hastada psikosomatik yansımalara neden olabilir. Sonuç olarak cinsel işlev bozukluğu görülen infertil hastaların psikiyatrik açıdan değerlendirilmesini öneriyoruz.

Anahtar Kelimeler: Erkek infertilitesi, Depresyon, Somatosensory Amplification, Erektil disfonksiyon.

\section{ABSTRACT}

OBJECTIVE: In this study, it was aimed to evaluate the relationship between erectile function score and depression and somatosensory amplification in patients presenting for primary male infertility.

MATERIAL and METHODS: Two hundred primary infertile patients who applied to the urology outpatient clinic to investigate infertility between February 2019 and May 2019 were included in the study.The patients were divided into two groups as IIEF $<26(n=61)$ and IIEF $\geq 26(n=$ 139) and evaluated. Sociodemographic data and psychiatric scale scores (Beck Depression Inventory, Somatosensory Amplification Scale) were compared between the groups and correlation analyzes were performed. RESULTS: The patients' age range was 18-45 (mean: 30.1). The mean duration of infertility in the group with IIEF $\geq 26$ was 21.6 months and there was a statistically significant difference $(p<0.001)$. When the SSAS and BDI scores were compared between the two groups, both scores were found to be significantly higher in the group with IIEF $<26$ and were $25.93 \pm 6.91,14.77 \pm 7.87$, respectively $(\mathrm{p}=0.024, \mathrm{p}<0.001$ ). The IIEF score correlated negatively with SSAS and BDI scores. Duration of infertility was correlated positively with SSAS and BDI and negatively with IIEF.

CONCLUSION: In infertility with male factor, sexual dysfunctions can be seen. These disorders can cause psychosomatic reflections in the patient. In conclusion, we recommend psychiatric evaluation of infertile patients with sexual dysfunction.

Keywords: Male infertility, Depression, Somatosensory Amplification, Erectile dysfunction.

\section{Gíriș}

İnfertilite, Dünya Sağlık Örgütü (WHO) tarafından, cinsel açıdan aktif bir çiftin en az 12 ay korunmasız ve düzenli cinsel birlikteliğe rağmen gebelik sağlayamaması olarak

'Bozok Üniversitesi Tıp Fakültesi, Üroloji Ana Bilim Dalı, Yozgat, Türkiye

${ }^{2}$ Tokat Devlet Hastanesi, Üroloji Bölümü, Tokat, Türkiye

\section{Yazışma Adresi/ Correspondence:}

Dr. Öğr. Üyesi Ünal Öztekin

Yozgat Bozok Üniversitesi, Uygulama ve Araştırma Hastanesi, Üroloji Anabilim Dalı,

Yozgat, Türkiye

Tel: $\quad+905303478578$

E-mail: dr_unal@hotmail.com

tanımlanmaktadır. ${ }^{[1]}$ Türkiye'de çiftlerin yaklaşık \%1020'si infertilite nedeni ile tedavi almaktadır. Olguların yaklaşık \%50'si erkek kaynaklıdır, \%30-40'ında ise eş faktörü normal iken, erkek faktörlü neden de bulunamaz ve idiopatik infertilite olarak tanımlanır. ${ }^{[2]}$ Ülkemizden yapılan 406 hastalık bir çalışmada erkek infertilitesi oranı $\% 45,6$, idiopatik infertilite oranı $\% 40,6$ olarak bildirilmiştir. ${ }^{[3]}$

Çocuk isteme arzusunun artması ve uzun dönem gebelik sağlanamaması durumu çiftler üzerinde sosyal, kültürel ve ekonomik açıdan olumsuz etkiler yaratabilir. ${ }^{[4]}$ Çiftlerin sadece gebelik elde edebilmek için cinsel birliktelik sağlaması da zaman içerisinde seksüel fonksiyonları olumsuz 
etkileyerek kaygı ve stres ile birlikte psikojenik bozukluklara neden olabilmektedir. Depresyon ve cinsel işlev bozukluğu arasındaki çift yönlü ilişkiyi inceleyen bir meta-analizde; cinsel işlev bozukluğu bildiren hastaların, depresyon belirtileri için rutin olarak taranması, depresyon belirtileri gösteren hastaların ise cinsel işlev bozukluğu açısından rutin olarak değerlendirilmesi gerekliliği önerilmiştir. ${ }^{[5]}$ Psikopatolojilerin cinsel işlev bozukluğuna etkisinin olabileceği ya da ortak bir biyolojik etiyolojiyi paylaştıklarını bildiren çalışmalarda mevcuttur. ${ }^{[6]}$

Bedensel duyumları abartma terimi; somatik duyumları yoğun, zararlı ve rahatsız edici olarak deneyimleme eğilimi olarak tanımlanmıştır. ${ }^{[7]}$ Yapılan çalışmalarda depresyon ile bedensel duyumları abartma arasında ilişki bildirilmiştir. ${ }^{[8]}$ Bizim bilgilerimize göre literatürde özellikle infertilite araştırılması nedeni ile başvuran ve cinsel işlev bozukluğu görülen hastalarda bedensel duyumları abartma konusunda literatürde çalışmaya rastlanmamıştır.

$\mathrm{Bu}$ çalışmada erkek infertilitesi araştırılmak üzere başvuran ve infertilite tanısı alan erkek hastalarda erektil fonksiyon ile depresyon ve bedensel duyumları abartma arasındaki ilişkinin değerlendirilmesi amaçlanmıştır.

\section{GEREC YÖNTEM}

Bu çalışmada Şubat 2019-Mayıs 2019 tarihleri arasında üroloji polikliniğine infertilite araştırılması nedeniyle başvuran hastalar değerlendirildi. Etik kurul onayı alındıktan sonra tüm hastalardan bilgilendirilmiş onam alındı ve Helsinki Deklarasyonu uyarınca çalışma retrospektif olarak yapıldı (2017-KAEK-189_2019.11.13_13). Hasta verileri, tıbbi kayıtlardan ve üroloji polikliniği, infertil hasta takip formlarından taranarak kayıt altına alındı. Kriterleri karşılayan 200 infertil hasta çalışmaya dâhil edildi. Uluslararası Erektil Fonksiyon İndeksi (IIEF) skoruna göre hastalar iki gruba ayrild. IIEF <26 ( $n=61)$ olan ve IIEF $\geq 26(n=139)$ olan hastalar, olmak üzere iki gruba ayrıldı. Gruplar arası sosyodemografik veriler ve psikiyatrik parametreler değerlendirildi.

Çalışmaya, 18-45 yaş arası en az bir yıllık düzenli cinsel birlikteliğe rağmen gebelik sağlayamayan ve eş faktörü normal olan, testleri doldurabilecek kognitif yetide olan, herhangi bir psikiyatrik veya nörolojik hastalık öyküsü olmayan hastalar dahil edildi. Hastaların sosyodemografik verileri; yaş, sigara içme durumu, infertilite süresi, eğitim süresi kayıt altına alındı. Cinsel işlev durumunu etkileyebilecek hormonal patolojisi (hipo/hipergonadizm, hipo/ hipertroidi, hiperprolaktinemi vb.), vücut kitle indeksi $\geq 30 \mathrm{~kg} / \mathrm{m}^{2}$, psikiyatrik ilaç kullanan, renal, hepatik, kardiyovasküler ve metabolik hastalığı olan, alkol ve madde bağımlılığı olan hastalar çalışma dışı bırakıldı.

\section{Değerlendirme Araçları}

Uluslararası Erektil Fonksiyon İndeksi (IIEF): IIEF formu 15 sorudan oluşan ereksiyon ve cinsel fonksiyon durumunu belirlemek için kullanılan bir ölçektir.1,2,3,4,5 ve 15 numaralı sorular erektil fonksiyonu değerlendirmek için kullanılır. Puanlama toplam 0-30 $(0-10=$ ciddi, 11-16=orta, $17-21=$ hafif-orta, $22-25=$ hafif, $26-30=$ yok) arasında değişmektedir. Yirmi altı ve üzeri normal erektil fonksiyon skoru olarak kabul edilir.

Beck Depresyon Ölçeği (BDI): Beck ve ark. ${ }^{\left[{ }^{9]}\right.}$ tarafından geliştirilmiş, 21 sorudan oluşan öz bildirim ölçeğidir. Her madde 0-3 arasında puanlanmaktadır ve toplam puan 0-63 arasında değişmektedir. Ülkemizde geçerlilik ve güvenilirlik çalışması yapılmıştır. ${ }^{[10]}$

\section{Somatosensory Amplification Scale (Bedensel Duyumları Abartma Ölçeği) (SSAS): Bedensel duyum- ları abartma ölçeği, Barsky ve ark. ${ }^{[11]}$ tarafından geliştirilen 10 maddeden oluşan, rahatsız edici bedensel duyumlara olan duyarlılığı ölçmek için kullanılan bir ölçektir. Her bir soru 1-5 arasında puanlanır. Toplam puan abartma puanı olarak değerlendirilir. Türkçe geçerlik ve güvenirlik çalış- ması yapılmıştır. ${ }^{[12]}$}

\section{istatistiksel Analiz}

İstatistiksel analiz, SPSS 25,0 (Statistical Package for Social Sciences, IBM Inc., Chicago, IL, USA) paket program kullanılarak yapılmıştır. Normallik dağılımların tespiti için Kolmogorov-Smirnov testi kullanılmıştır. Normal dağıllım gösteren numerik değişkenlerin iki grup arası karşılaştırmalarında Bağımsız Gruplar $t$ Test, normal dağılım göstermeyen numerik değişkenlerin iki grup arası karşılaştırmalarında Mann Whitney U Testi kullanıldı. Gruplar arası korelasyon değerlendirilmesinde Spearman's korelasyon testi kullanıldı. İstatistiksel anlamlılık $\mathrm{p}<0,05$ olarak kabul edildi.

\section{BULGULAR}

Çalışmaya, yaş aralığı 18-45 (mean: 30,1) olan toplam 200 hasta dahil edildi. İki grup arasında yaş ve sigara içme oranı arasında istatistiksel olarak anlamlı fark yoktu. Altmış bir $(\% 30,5)$ infertil hastanın IIEF skoru <26 idi, $139(\% 69,5)$ hastanın IIFF skoru $\geq 26$ idi. İnfertilite süresi IIEF $<26$ olan grupta ortalama 43,2 ay, IIEF $\geq 26$ olan grupta ortalama 21,6 ay idi ve istatistiksel anlaml fark mevcuttu $(\mathrm{p}<0,001)$. İki grup arasında SSAS ve BDI skorları karşılaştırıldığında, her iki skor IIEF <26 olan grupta anlamlı derecede yüksekti ve sırası ile $25,93 \pm 6,91,14,77 \pm 7,87$ idi $(\mathrm{p}=0,024, \mathrm{p}<0,001) \quad($ Tablo 1). 
Ölçek skorları ile hasta verileri arasındaki korelasyonlar incelendiğinde; Yaş ve eğitim süresinin ölçek skorları ile arasında anlamlı bir korelasyon saptanmadı. IIEF skoru, SSAS ve BDI skorları ile anlamlı negatif korelasyon gösteriyordu. İnfertilite süresi, SSAS ve BDI ile pozitif, IIEF ile negatif korele idi (Tablo 2).

\section{TARTIŞMA}

İnfertilite, dünya nüfusunun 1/7'sini etkileyerek önemli finansal maliyetlere ve duygusal strese neden olabilecek bir durumdur. ${ }^{[13]}$ İnfertilitenin teşhisi ve tedavi planlaması, çiftlerde psikolojik stres, anksiyete ve depresyona neden olabilir. ${ }^{[14]} \mathrm{Bu}$ çiftlerde depresif bozuklukların daha sık görüldüğünü savunan çalışmalar mevcuttur. ${ }^{[15,16]}$ Çocuk istemi nedeni ile başvuran çiftleri poliklinik şartlarında değerlendirirken, cinsel fonksiyonlar ile kaygı ve stres bozukluklarının eşlik edebileceği akılda tutulmalıdır. Yoğun poliklinik şartlarında bu çiftler değerlendirilirken, infertilite etiyolojisine ve tedavi seçeneklerine odaklanılması, cinsel fonksiyon ve psikojenik bozuklukların atlanmasına neden olabilmektedir. Çiftlerde oluşan depresif bozukluklar, cinsel açıdan çiftleri olumsuz yönde etkileyebileceği gibi, ereksiyon kusuru yaşayan erkek hastalarda da psikojenik bozukluklar görülebilir. Literatürde, depresyon varlı̆̆ının cinsel işlev bozukluğu riskini $\% 50-70$ oranında, cinsel işlev bozukluğunun ise depresyon gelişme riskini \%130-210 oranında arttırdığı bildirilmiştir. ${ }^{[5]}$

Depresyondan kaynaklanan cinsel işlev bozukluğu, sosyal hayattan çekilmeye, performans kaygısına ve daha şiddetli ve kalıcı bir depresyon uyandıran cinsel isteksizliğe neden olabilir. Geleneksel toplumlarda üremeye ve ailenin sürekliliğine büyük önem verilmekte ve çiftler, aile ve toplum baskısını üzerlerinde yüksek oranda hissetmektedirler. ${ }^{[17]}$ İnfertil olarak teşhis edilmek veya infertil bir çiftin bir üyesi olmak, çeşitli cinsel ve psikolojik problemler yaratabilir. Bununla ilgili olarak Smith ve ark. ${ }^{[18]}$ yaptığı bir çalışmada özellikle erkek faktörlü infertilitede sosyal baskının da etkisi ile hayat

Tablo 1. IIEF skoruna göre grupların demografik ve psikiyatrik karakteristikleri

\begin{tabular}{|c|c|c|c|}
\hline & $I E F F<26(n=61)$ & $I E F F \geq 26(n=139)$ & $P$ value \\
\hline Yaş (mean $\pm S D)$ & $30.18 \pm 4.24$ & $29.05 \pm 4.95$ & 0.106 \\
\hline Sigara içme oranı (\%) (n) & $\% 47.5(66)$ & $47.5 \%(29)$ & 0.994 \\
\hline İnfertilite Süresi (ay)(mean $\pm S D)$ & $43.23 \pm 49.14$ & $21.63 \pm 14.67$ & $<0.001$ \\
\hline SSAS & $25.93 \pm 6.91$ & $23.28 \pm 7.84$ & 0.024 \\
\hline BDI & $14.77 \pm 7.87$ & $10.46 \pm 7.67$ & $<0.001$ \\
\hline
\end{tabular}

SSAS, bedensel duyumları abartma ölçeği; BDI, Beck depresyon ölçeği; IIEF, uluslararası erektil fonksiyon indeksi

Tablo 2. IIEF, BDAÖ ve BDÖ ile sosyodemografik veriler arası korelasyon

\begin{tabular}{|c|c|c|c|c|c|c|}
\hline & \multicolumn{2}{|c|}{ SSAS } & \multicolumn{2}{|c|}{$B D I$} & \multicolumn{2}{|c|}{ IIEF } \\
\hline & $r$ & $p$ & $r$ & $p$ & $r$ & $p$ \\
\hline Yaş & -0.090 & 0.205 & 0.061 & 0.391 & -0.059 & 0.403 \\
\hline Eğitim Süresi (yıl) & -0.018 & 0.798 & -0.016 & 0.827 & 0.131 & 0.065 \\
\hline İnfertilite Süresi (ay) & 0.271 & $<0.001$ & 0.170 & 0.016 & -0.289 & $<0.001$ \\
\hline IEFF & -0.214 & 0.002 & -0.300 & $<0.001$ & & \\
\hline
\end{tabular}

SSAS, bedensel duyumları abartma ölçeği; BDI, Beck depresyon ölçeği; IIEF, uluslararası erektil fonksiyon indeksi

kalitesinin ve cinsel fonksiyonların negatif etkilendiği vurgulanmıştır. Bu negatif etki, psikojenik durumun olumsuz etkilendiği hasta popülasyonu olarak karşımıza çıkabilir. Nitekim çalışmamızda ED görülen grupta depresyon skoru, ED görülmeyen hastalara göre anlamlı derecede yüksek olarak izlenmiştir. Korelasyon incelememizde özellikle çocuk isteme arzusunun ve infertilite süresinin uzaması, erektil fonksiyon skoru ile negatif yönde, psikolojik ölçek skorları ile pozitif yönde korele olarak izlenmektedir. Benzer şekilde Ramezanzadeh ve ark. ${ }^{[19]}$ yaptıkları çalışmada da infertilite süresi ile seksüel fonksiyonlar arasında ters ilişki olduğu bildirilmiştir. Ancak infertilitenin cinsel işlevler üzerinde olumsuz bir etkisinin olmadığını savunan çalışmalarda mevcuttur. [20,21] Çalışmaya aldığımız toplam 200 infertil hastanın 61 $(\% 30,5)$ 'inde erektil disfonksiyon (ED) görüldü. Literatür verileri ve çalışmamızın sonuçları birlikte değerlendirildiğinde, infertilite süresine bağlı olarak ile ED görülme sıklığının arttığı ve buna bağlı olarak cinsel problemler ile birlikte depresif bozuklukların görülme olasılı̆̆ının daha fazla olduğu söylenebilir. 
Bedensel duyumları abartmanın kaygı, depresyon ve genel psikopatoloji ile ilişkili olduğu varsayılmaktadır. ${ }^{\left[{ }^{[]}\right.}$ Literatürde, majör depresif bozukluklarda, kaygı ve depresyon kontrolünün ardından SSAS'nin belirgin şekilde azaldığını vurgulayan çalışmalar mevcuttur. Sayar ve ark. ${ }^{[22]}$ fibromiyalji ve majör depresyonu olan iki ayrı hasta grubunda, antidepresan tedavi öncesinde ve sonrasında, SSAS skorundaki değişimleri değerlendirdikleri çalışmalarında, major depresyon ile takip edilen hasta grubunda tedavi sonrası SSAS skoru anlamlı düşüş gösterirken, fibromiyalji ile takip edilen grupta anlamlı değişim izlenmediğini vurgulamışlardır. Çalışmamızda ED ile birlikte, bu gruptaki BDI ve beraberinde SSAS skorlarının arttığı görülmüştür. Literatürde, infertilite, cinsel işlev bozukluğu ve bedensel duyumları algılama konusunda yeterli çalışma bulunmamaktadır. Sonuçlarımız infertil hastalarda depresyona eşlik eden beden duyumlarının da abartılı şekilde algılandığını göstermektedir. İnfertilite, teşhis ve tedavi sürecinde, tekrarlayan tetkiklerin yapılmasını gerektiren bir durumdur. Hastalar zaman zaman başarısızlıkla sonuçlanabilen tedavi girişimleri ve uzun zaman alabilen tekrarlayan tıbbi incelemelere maruz kalabilmektedir. Yaşanan bu süreç anksiyeteyi arttırarak, sağlıkla ilgili kaygılara ve somatik duyumları daha abartılı algılamaya neden olabilir.

Çalışmamızın, retrospektif şekilde dizaynı, tek merkezli yapılmış olması, fertil ve erektil fonksiyonu normal olan kontrol grubunun olmaması çalışmamızın limitasyonları arasında sayılabilir.

\section{SONUÇ}

Çalışmamızda erkek primer infertil hastalarda cinsel işlev durumuna göre psikolojik durum analizi yapıldı. Ereksiyon problemi yaşayan infertil hastalarda depresyon ve bedensel durumları abartma skorunun anlamlı derecede yüksek olduğu görüldü. Ayrıca infertilite süresi uzadıkça erektil disfonksiyon, depresyon ve somatik duyumların abartılı şekilde algılanmasının arttığı sonucuna ulaşıldı. Sonuç olarak erkek faktörlü infertilite araştırılması nedeni ile başvuran tüm hastaların, ereksiyon kusurlarının olabileceği aynı zamanda bu durumun psikolojik rahatsılıkların görülme sıklığını artırabileceği akılda tutulmalıdır. Tüm infertil hastaların cinsel fonksiyonlar yönünden sorgulanması gerektiğini ve bu hastaların psikiyatrik yönden değerlendirilmesini öneriyoruz.

Bu konuda daha büyük örnekleme sahip, çok merkezli, ayrıca infertilite tedavisi sonrası gebelik sağlanan çiftlerinde çalışmaya dahil edilerek semptom skorlarındaki değişimlerinde değerlendirildiği uzun süreli randomize prospektif çalışmalara ihtiyaç vardır.

\section{Hakem Değerlendirmesi}

Dış bağımsız

Çıkar Çatışması

Yazarlar çıkar ilişkisi olmadığını beyan etmişlerdir.

\section{Finansal Destek}

Herhangi bir mali destek alınmamıştır.

\section{Peer-review}

Externally peer-reviewed.

\section{Conflict of Interest}

No conflict of interest was declared by the authors.

Financial Disclosure

No financial disclosure was received.

\section{KAYNAKLAR}

1. Rowe PJ. WHO manual for the standardized investigation, diagnosis, and management of the infertile male. Cambridge, U. K.: Organization WH.; 2000. p.91.

2. Jungwirth A, Giwercman A, Tournaye H, Diemer T, Kopa Z, Dohle G, Krausz C. European Association of Urology guidelines on Male Infertility: the 2012 update. Eur Urol 2012;62:324-32. [CrossRef]

3. Oztekin U, Caniklioglu M, Sari S, Selmi V, Gurel A, Isikay L. Evaluation of Male Infertility Prevalence with Clinical Outcomes in Middle Anatolian Region. Cureus 2019;11:5122. [CrossRef]

4. Ozkan B, Orhan E, Aktas N, Coskuner ER. Sexual dysfunction and depression among Turkish women with infertile husbands: the invisible part of the iceberg. Int Urol Nephrol 2016;48:31-6. [CrossRef]

5. Atlantis E, Sullivan T. Bidirectional association between depression and sexual dysfunction: a systematic review and meta-analysis. J Sex Med 2012;9:1497-507. [CrossRef]

6. Kennedy SH, Rizvi S. Sexual dysfunction, depression, and the impact of antidepressants. J Clin Psychopharmacol 2009;29:157-64. [CrossRef]

7. Barsky AJ, Goodson JD, Lane RS, Cleary PD. The amplification of somatic symptoms. Psychosom Med 1988;50:510-9. [CrossRef]

8. Koteles F, Witthoft M. Somatosensory amplification - An old construct from a new perspective. J Psychosom Res 2017;101:1-9. [CrossRef]

9. Beck AT, Ward CH, Mendelson M, Mock J, Erbaugh J. An inventory for measuring depression. Arch Gen Psychiatry 1961;4:561-71. [CrossRef]

10. Hisli N. Beck Depresyon Envanterinin geçerliliği üzerine bir çalışma. Turk Psikol Derg 1988;22:118-26.

11. Barsky AJ, Wyshak G, Klerman GL. The somatosensory amplification scale and its relationship to hypochondriasis. J Psychiatr Res 1990;24:323-34. [CrossRef]

12. Gulec H, Sayar K. Reliability and validity of the Turkish form of the Somatosensory Amplification Scale. Psychiatry Clin Neurosci 2007;61:25-30. [CrossRef]

13. Aston Kl, Krausz C, Laface I, Ruiz-Castane E, Carrell DT. Evaluation of 172 candidate polymorphisms for association with oligozoospermia or azoospermia in a large cohort of men of European descent. Hum Reprod 2010;25:1383-97. [CrossRef]

14. Cunningham J. Infertility: A primer for primary care providers. JAAPA 2017;30:19-25. [CrossRef]

15. Klemetti R, Raitanen J, Sihvo S, Saarni S, Koponen P. Infertility, mental disorders and well-being--a nationwide survey. Acta Obstet Gynecol Scand 2010;89:677-82. [CrossRef]

16. Yang B, Zhang J, Qi Y, Wang P, Jiang R, Li H. Assessment on Occurrences of Depression and Anxiety and Associated Risk Factors in the Infertile Chinese Men. Am J Mens Health 2017;11:767-74. [CrossRef]

17. Gunay O, Cetinkaya F, Nacar M, Aydin T. Modern and traditional practices of Turkish infertile couples. Eur J Contracept Reprod Health Care 2005;10:105-10. [CrossRef]

18. Smith JF, Walsh TJ, Shindel AW, Turek PJ, Wing H, Pasch L, Katz PP. Sexual, marital, and social impact of a man's perceived infertility diagnosis. J Sex Med 2009;6:2505-15. [CrossRef] 
19. Ramezanzadeh F, Aghssa MM, Jafarabadi M, Zayeri F. Alterations of sexual desire and satisfaction in male partners of infertile couples. Fertil Steril 2006;85:139-43. [CrossRef]

20. Khademi A, Alleyassin A, Amini M, Ghaemi M. Evaluation of sexual dysfunction prevalence in infertile couples. J Sex Med 2008;5:1402-10. [CrossRef]
21. Muller MJ, Schilling G, Haidl G. Sexual satisfaction in male infertility. Arch Androl 1999;42:137-43. [CrossRef]

22. Sayar K, Barsky AJ, Gulec H. Does somatosensory amplification decrease with antidepressant treatment? Psychosomatics 2005;46:340-4. [CrossRef] 